\title{
A brief overview on grain growth of bulk electrodeposited nanocrystalline nickel and nickel-iron alloys
}

https://doi.org/10.1515/rams-2019-0011

Received Jan 18, 2018; accepted Oct 04, 2018

\begin{abstract}
This review focuses on grain growth behaviors and the underlying mechanisms of bulk electrodeposited nanocrystalline nickel and nickel-iron alloys. Effects of some important factors on grain growth are described. During thermal-induced grain growth process, grain boundary migration plays a key role. For similar thermal conditions, due to grain boundary mobility with solute drag, limited grain growth occurs in nanocrystalline alloys, as compared to pure metals. Nonetheless, in the case of stressinduced grain growth process, there are a variety of mechanisms in samples having various deformation histories.

As an example the grain growth of nanocrystalline nickel and $\mathrm{Ni}-20 \% \mathrm{Fe}$ alloy with nearly the same grain-size distribution and average grain size is compared in this paper. Thermal analysis indicates nanocrystalline nickel is much more prone to rapid grain growth than nanocrystalline $\mathrm{Ni}-20 \% \mathrm{Fe}$ alloy. Nevertheless, grain growth of nanocrystalline $\mathrm{Ni}-20 \% \mathrm{Fe}$ is found to be more pronounced than nanocrystalline nickel during rolling deformation.
\end{abstract}

Keywords: Grain Growth; Nanocrystalline; Nickel; NickelIron alloy

\section{Introduction}

Nanocrystalline (NC) metals and alloys, as a typical species of advanced materials, have gradually become one

\footnotetext{
${ }^{\star}$ Corresponding Author: Haitao Ni: College of Materials and Chemical Engineering, Chongqing University of Arts and Sciences, Yongchuan, Chongqing 402160, China; Email: htniok@163.com Xiyan Zhang: College of Materials Science and Engineering, Chongqing University, Chongqing 400044, China; Email: kehen888@163.com

Jiang Zhu, Zhaodong Wang, Haiyang Lv, Yongyao Su: College of Materials and Chemical Engineering, Chongqing University of Arts and Sciences, Yongchuan, Chongqing 402160, China
}

¿ Open Access. (c) 2019 H. Ni et al., published by De Gruyter. (cc) BY License of the hot topics in the research field of materials and mechanics because of their outstanding mechanical, physical and chemical properties. However, from the point of view of the energy, the nano-grain boundaries with a higher energy level are well known to be unstable, leading to the microstructures and properties stabilities of nanomaterials are inferior to ordinary coarse-grain materials, and then severely restricting the wide application of nanomaterials. Throughout the research reports on NC metals and alloys, as a significant feature of nanomaterials, grain size has generally been a key issue in the investigation of microstructure and performance stability of nanoscale materials [1-7]. Most theoretical and experimental investigations have revealed the grain size-deformation mechanism relationship [4, 8-10]. For example, the results of molecular dynamic simulations have shown that grain boundary sliding and rotation play a key role at very fine grain sizes (typically below $\sim 10 \mathrm{~nm}$ ), while partial dislocations emission from grain boundaries at the grain sizes in the range of $\sim 10-50 \mathrm{~nm}$. For people in the materials community controlling grain size is a fundamental problem in nanoscale materials science. Furthermore, several interesting discussions about the termination of grain growth are also made $[11,12]$.

Although a great deal of research work has been done and meaningful results have been achieved in the study of the growth behavior of NC grains, there are still some doubts to be studied. One of the most important controversies is whether or not the observed grain growth during deformation of $\mathrm{NC}$ metals is the result of purely strain induced grain boundary motion. Moreover, there is also some evidence to suggest that the preparation/synthesis methods of bulk NC metals could affect the grain growth behavior. In the present contribution the review provides a brief overview of grain growth or coarsening in bulk electrodeposited $\mathrm{NC}$ nickel (Ni) and nickel-iron (Ni-Fe) alloys, expecting to be useful to better understand microstructural stability of nanoscale materials.

This work is licensed under the Creative Commons Attribution 4.0 
Table 1: A short summary of the grain size change for bulk electrodeposited NC Ni and Ni-Fe alloys after isothermal annealing process at different temperatures and times.

\begin{tabular}{cccccc}
\hline Sample & $\begin{array}{c}\text { Initial average } \\
\text { grain size }(\mathrm{nm})\end{array}$ & $\begin{array}{c}\text { Heat temperature } \\
(\mathrm{K})\end{array}$ & $\begin{array}{c}\text { Holding time } \\
(\mathrm{h})\end{array}$ & $\begin{array}{c}\text { Final average grain } \\
\text { size }(\mathrm{nm})\end{array}$ & Ref. \\
\hline $\mathrm{Ni}$ & 10 & 393 & 0.5 & $10-20,40^{\star}$ & {$[13]$} \\
$\mathrm{Ni}$ & 10 & 493 & 0.5 & $10-20,50-130^{\star}$ & {$[13]$} \\
$\mathrm{Ni}$ & 10 & 593 & 0.5 & $300-600$ & {$[13]$} \\
$\mathrm{Ni}$ & 10 & 693 & 0.5 & $400-800$ & {$[13]$} \\
$\mathrm{Ni}$ & $18 \pm 2$ & 393 & 1 & $20.5 \pm 2$ & {$[22]$} \\
$\mathrm{Ni}$ & $18 \pm 2$ & 493 & 1 & $22 \pm 2^{*}$ & {$[22]$} \\
$\mathrm{Ni}$ & $18 \pm 2$ & 593 & 1 & $26 \pm 2$ & {$[22]$} \\
$\mathrm{Ni}$ & $18 \pm 2$ & 693 & 1 & $29 \pm 3$ & {$[22]$} \\
$\mathrm{Ni}$ & $29 \pm 8$ & 373 & 1 & $31 \pm 6$ & {$[17]$} \\
$\mathrm{Ni}$ & $29 \pm 8$ & 473 & 1 & $\sim 75, \sim 275^{*}$ & {$[17]$} \\
$\mathrm{Ni}$ & $29 \pm 8$ & 573 & 1 & $\sim-2 \mu \mathrm{m}$ & {$[17]$} \\
$\mathrm{Ni}-5.7 \% \mathrm{Fe}$ & $\sim 8$ & 473 & 2 & $\sim 19$ & {$[27]$} \\
$\mathrm{Ni}-5.7 \% \mathrm{Fe}$ & $\sim 8$ & 573 & 2 & $\sim 12$ & {$[27]$} \\
$\mathrm{Ni}-8.8 \% \mathrm{Fe}$ & $\sim 10$ & 473 & 2 & $\sim 80$ & {$[27]$} \\
$\mathrm{Ni}-8.8 \% \mathrm{Fe}$ & $\sim 10$ & 573 & 2 & $\sim 9$ & {$[27]$} \\
$\mathrm{Ni}-17.7 \% \mathrm{Fe}$ & $\sim 12$ & 473 & 2 & $\sim 30$ & {$[27]$} \\
$\mathrm{Ni}-17.7 \% \mathrm{Fe}$ & $\sim 12$ & 573 & 2 & 13.4 & {$[28]$} \\
$\mathrm{Ni}-21 \% \mathrm{Fe}$ & 13.4 & 373 & 1.5 & 22 & {$[28]$} \\
$\mathrm{Ni}-21 \% \mathrm{Fe}$ & 13.4 & 573 & 1.5 & 45 & {$[28]$} \\
$\mathrm{Ni}-21 \% \mathrm{Fe}$ & 13.4 & 673 & 1.5 & 6 & {$[29]$} \\
$\mathrm{Ni}-45 \% \mathrm{Fe}$ & 5 & 573 & 1 & 17 & {$[29]$} \\
$\mathrm{Ni}-45 \% \mathrm{Fe}$ & 5 & 673 & 20 & 20 & {$[29]$} \\
$\mathrm{Ni}-45 \% \mathrm{Fe}$ & 5 & 573 & 20 & & {$[29]$} \\
$\mathrm{Ni}-45 \% \mathrm{Fe}$ & 5 & 673 & & & \\
\hline
\end{tabular}

«bimodal distribution

\section{Grain growth behaviors and the underlying mechanisms}

\subsection{Thermally-induced grain growth}

Thermally-induced grain growth has been supported by the majority of experimental results so far [13-26]. A short summary of the grain size evolution during isothermal annealing of bulk electrodeposited NC Ni and Ni-Fe alloys is given in Table 1. It is found the nanograins are prone to coarsening at elevated temperature, especially under high temperature conditions.

Despite that the growth behavior of nanograins is a pretty complex question, it is well known that the temperature effect should generally be taken into account in growth process. On the basis of classical grain growth theory, grain growth during the heat treatment of nanomaterials is most commonly thought of as a thermally-activated grain boundary diffusion process. In particular, the role of grain boundary diffusion in grain growth of NC Ni during nonisothermal annealing has been studied [30]. The results revealed that there is no obvious difference in the activation energy between anomalous grain growth and grain boundary diffusion. The atomic displacement during the grain growth was based exclusively on atomic diffusion along grain boundaries. Some research reports have also clearly shown such diffusional boundary mobility will decreases exponentially with decreasing temperature [31]. At low temperatures, grain boundary activities including migration, sliding and diffusion will be suppressed. Since such limited grain boundary mobility, the grains of most NC metals and their alloys are relatively stable. Beyond that, subjected to the same thermal condition, NC pure metals tend to be less stable than their alloys from the thermodynamic point of view [32]. Among the variety of $\mathrm{NC} \mathrm{Ni}$ and $\mathrm{Ni}-\mathrm{Fe}$ electrodeposits, it is proved that the initiation temperatures of grain growth have little correlation with the initial grain size of as-deposited 
Table 2: A short summary of the grain size change for bulk electrodeposited NC Ni and Ni-Fe alloys after deformation treatment.

\begin{tabular}{|c|c|c|c|c|c|}
\hline Sample & $\begin{array}{l}\text { Initial average grain } \\
\text { size }(\mathrm{nm})\end{array}$ & Deformation mode & $\begin{array}{l}\text { Deformation } \\
\text { ratio/equivalent von } \\
\text { Mises strain }\end{array}$ & $\begin{array}{l}\text { Final average grain } \\
\text { size }(\mathrm{nm})\end{array}$ & Ref. \\
\hline $\mathrm{Ni}$ & 19 & compression & $14 \%$ & $50-250$ & [47] \\
\hline $\mathrm{Ni}$ & $23.8 \pm 6.2$ & tension & $3-4 \%$ & $24.6 \pm 8.1$ & [51] \\
\hline $\mathrm{Ni}$ & $\sim 20$ & $\mathrm{RT}$ rolled & $90 \%(\epsilon=2.3)$ & $\sim 35$ & [43] \\
\hline $\mathrm{Ni}$ & $\sim 20$ & cryo rolled & $90 \%(\epsilon=2.3)$ & $\sim 20$ & [43] \\
\hline $\mathrm{Ni}$ & $\sim 24$ & cryo rolled & 0.4 & $\sim 28$ & [44] \\
\hline $\mathrm{Ni}$ & $\sim 24$ & cryo rolled & 0.9 & $\sim 38$ & [44] \\
\hline $\mathrm{Ni}-18 \% \mathrm{Fe}$ & $14 \pm 1$ & LNT rolled & $\sim 0.36$ & $26 \pm 3$ & [42] \\
\hline $\mathrm{Ni}-18 \% \mathrm{Fe}$ & $14 \pm 1$ & RT rolled & $\sim 0.6$ & $31 \pm 3$ & [42] \\
\hline $\mathrm{Ni}-20 \% \mathrm{Fe}$ & $10-20$ & $\begin{array}{l}\text { quasi-static } \\
\text { compression }\end{array}$ & $\sim 8 \%$ & 23 & [60] \\
\hline $\mathrm{Ni}-20 \% \mathrm{Fe}$ & $10-20$ & $\begin{array}{l}\text { Uniaxial dynamic } \\
\text { compression }\end{array}$ & $\sim 22 \%$ & $18-35$ & [60] \\
\hline $\mathrm{Ni}-20 \% \mathrm{Fe}$ & $\sim 22$ & $\begin{array}{l}\text { high-pressure } \\
\text { torsion }\end{array}$ & $\sim 26$ & $\sim 95$ & [21] \\
\hline $\mathrm{Ni}-21 \% \mathrm{Fe}$ & $\sim 21$ & $\begin{array}{l}\text { high-pressure } \\
\text { torsion }\end{array}$ & $\sim 230$ & $\sim 53$ & [61] \\
\hline $\mathrm{Ni}-30 \% \mathrm{Fe}$ & $\sim 18$ & RT rolled & 0.22 & $\sim 77$ & [62] \\
\hline
\end{tabular}

sample, but much with impurity content and iron content. Furthermore, the initiation temperature of grain growth will generally shift to higher values with increasing impurity content or iron content. This universal phenomenon could be well explained by the theory of grain boundaries. The impurities such as sulfur or solute atoms can significantly contribute to the stability of nanograins by either pinning or introducing a drag force on grain boundaries $[12,28,33,34]$. Therefore, only very limited grain growth can occur, even at a relatively higher temperature.

In addition to the above, it is also worth noting that there are still some differences exist on samples with different initial grain orientations or microstructural defects [35-37]. It has been shown that grain growth is not only a coarsening process but also an orientation selective process. The orientation-dependent grain growth has been found in NC metals, which can be attributed to the orientation dependence of grain boundary energy and mobility [37-40]. According to the grain boundary energy distribution, since the (111) oriented grains have the lowest energy, it is easily concluded that the (111) oriented nanograins should grow at the expense of other oriented nanograins. On the other hand, twinning is regarded as yet another special mode of energy minimization. From the literature of molecular dynamics simulations of grain growth in annealed $\mathrm{NC} \mathrm{Ni}$, it was found that grain growth can be accompanied by the generation of coherent twin boundary [41]. As the nanograins grow, twins will collide and then form twin junctions. Such coherent twin boundary junctions, especially five-fold twin junctions, tend to retard the grain growth process.

\subsection{Stress-induced grain growth}

The nanograin growth behaviors have been commonly observed in various deformation processes, such as cold rolling [42-46], compression [24, 47-49], tension [50-52], indentation [53], high-pressure torsion $[17,54,55]$ and cyclic/fatigue deformation [56-58]. Deserve to be mentioned, various deformations have been performed on NC $\mathrm{Ni}$ samples from the same source, and grain growth occur to varying degrees [59]. Among the studies devoted to the microstructural evolution of deformed NC samples, a short summary of the grain size values for bulk electrodeposited NC Ni and Ni-Fe alloys before and after deformation treatment is partly listed in Table 2. Under an applied stress, one phenomenon that may be of particular interest is the nanograins are still showing a tendency to destabilize at room temperature, even at liquid-nitrogen temperature. To elucidate the stress-induced grain growth, several models and underlying mechanisms are proposed. These mechanisms include stress-induced grain bound- 
ary motion (particularly migration and/or sliding) $[55,63$, 64], dislocation-grain boundary interaction [45, 65], grain rotation [52, 66, 67], free surface assisted stress-driven grain growth (or self-mechanical annealing) [68], stressheterogeneity-relieving mechanism [69], and so on.

Based on energy considerations, due to large volume fractions of grain boundary, and a lot of free surface at grain boundaries, the grain growth of NC metals can happen easily and quickly during deformation especially under the conditions of relatively high deformation strains $[68,70,71]$. Nonetheless, it seems likely that there do exist a critical level of deformation/strain energy to enable grain growth. Besides, no obvious grain growth during uniaxial compression of NC Ni suggests that the complex stress state as well as strain gradient plasticity plays an important role in the process of grain growth induced by deformation [48].

Stress-induced grain boundary motion has been observed in a direct experiment, as well as predicted by theory and molecular dynamics simulations [71-73]. The grain boundary migration during plastic deformation of $\mathrm{NC} \mathrm{Ni} \mathrm{with} \mathrm{an} \mathrm{average} \mathrm{grain} \mathrm{size} \mathrm{of} 5 \mathrm{~nm}$ has been probed by large scale molecular dynamics simulations [72]. From the atomic scale processes analysis, it is concluded that grain growth by grain boundary migration could be purely induced by stress at low temperature. Another simulation results on NC metals with an average grain size of $15 \mathrm{~nm}$ reveal that grain rotation could play an equally important role, at least during the early stages of grain growth, besides the conventional curvature-driven grain-boundary migration dominated mechanism developed for its coarsegrained counterpart [74].

During the deformation process, a great deal of crystal defects and deformation energy will be introduced, resulting in a higher grain boundary energy. To reduce the excess energy, grain rotation and/or grain growth has been recognized as a basic mode [75]. Considering grain rotation can induce a change in the grain orientation, grain orientation could also have affected the growth behavior of nanograins $[46,49]$.The physical model for deformationinduces grain rotation/growth has revealed that the slip and climb of grain boundary dislocations plays a major role in grain rotation process [52]. Under the joint action of grain boundary sliding and dislocation movement, the orientation of adjacent grains have gradually become nearly the same by grain rotation, thereby allowing the grain growth to occur by nanograins coalesce. In this regard, our previous investigations have clearly indicated the dislocation activity in some nanograins of the deformed $\mathrm{NC} \mathrm{Ni}$ sample with a rolling strain of 0.45 [76]. As shown in Figure 1a, pronounced grain coarsening is indeed largely ob- served after deformation. Further analysis of grain growth mechanism is depicted in Figure $1 \mathrm{~b}$ and Figure $1 \mathrm{c}$, in which the grain rotation and dislocation motion play an important role in the grain growth.
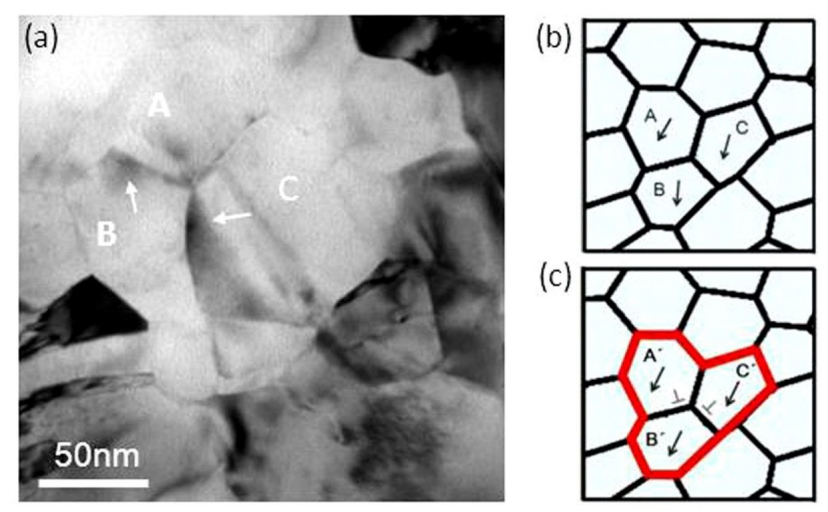

Figure 1: (a) Typical bright-field TEM image showing three grains, labeled as A, B, and C, in the cold-rolled NC Ni sample. Some trace of dislocation motion is shown in grains bywhite arrows. The corresponding schematic diagrams of grain coalesce by grain rotation and dislocation motion are shown in (b) and (c). The orientation of grains is indicated by black arrows.

On the other hand, with regard to the nanograin growth during deformation process, some researchers considered that grain growth is the result of deformation heat. The heat generated by the deformation can not only make nanograin grow, but also promote dislocation recovery. Therefore, it's easy to understand the decrease in strength of NC metals appears in the last stage of deformation. In order to suppress effectively dynamic recovery, ultralow-temperature liquid nitrogen was introduced into deformation process. The grain growth behavior of electrodeposited NC Ni with an initial average grain size of 20nm during cryogenic rolling deformation has been conducted [44]. The results indicated that nanograins remain unstable at liquid nitrogen temperature and grow during deformation in a confined manner. Especially when the deformation strains exceed $\sim 0.45$, average grain size increases significantly with further increasing strains.

In light of grain growth occurs during deformation at room temperature or liquid nitrogen temperature, it is often difficult to identify the role of thermal activation process during the growth of nanograins. Take the case of indentation deformation, since an ultra-low load is used, it is generally considered that grain growth is mostly induced by stress and with no thermal effect [18]. Such athermal grain growth during deformation is also found in other deformation modes at ambient or cryogenic temperatures $[56,77]$. The synthetic driving force molecular dy- 
namics simulation of grain boundary migration in Ni sample has shown that over $25 \%$ of the grain boundary types can undergo athermally activated motion, dominated by a coupled shear mechanism [78]. Nevertheless, an inverse relationship existed between load and temperature has been found recently in the pre-annealed NC Ni with an average grain size of 30nm [79]. The indentation load required for grain growth decreases with an increase in temperature, suggesting strongly that such concurrent grain growth is a deformation-induced thermally activated process.

Considered that grain growth and deformation are always coexistent and affect each other, the second purpose of this paper is to examine the grain growth behaviors of NC Ni and Ni-Fe alloys by contrast. The first attempt of the comparative analysis on grain size evolution was made in our previous investigation [80]. It has been previously shown that there is a considerable difference in grain growth rate between $\mathrm{NC} \mathrm{Ni}$ and Ni-Fe alloys.

\section{Experimental}

Bulk NC Ni and Ni-Fe alloy with 20 weight percent Fe were obtained by electrodeposition technology according to synthetic procedures already reported in previous literature [81, 82]. The deposit conditions were modified to get a similar level of grain size as far as possible for the comparative investigation. Modified Watts-type bath formulations were chosen for electrodepositing NC coatings onto a well-polished and activated mild steel substrate (cathode). Each bath contained nickel sulfate, boric acid, sodium chloride, saccharin and sodium dodecyl sulfate. In order to obtain the specified $\mathrm{Ni} / \mathrm{Fe}$ ion ratio, typical of $\mathrm{Ni}-\mathrm{Fe}$ alloy electroplating baths was composed of ferric sulfate. All the chemical reagents used were analytically pure and dissolved in deionized water. During the electrodepositing, electrolytic nickel plate with purity of $99.99 \%$ was used as anode. The temperature of electrodeposition baths was kept at $60^{\circ} \mathrm{C}$. The applied current density was DC $10 \mathrm{~A} / \mathrm{dm}^{2}$ and $7 \mathrm{~A} / \mathrm{dm}^{2}$ for $\mathrm{Ni}$ and Ni-Fe alloy, respectively. The $\mathrm{pH}$ value was adjusted by adding sulphuric acid up to the required value with the error of \pm 0.1 . After the electrodeposition was completed, the NC coatings were carefully stripped from mild steel substrate. The nominal composition of Ni-20 wt $\%$ Fe was determined by energy dispersive X-ray spectroscopy. Prior to deformation processing, the thickness of each sample sheet in as-received state was measured to be $\sim 0.15 \mathrm{~mm}$. For each sample, a rectangular section with the dimensions $5 \mathrm{~mm}$ (width) $\times 6 \mathrm{~mm}$ (length) was cut and cold-rolled at room temperature to various strains $(0.05,0.10,0.15)$ using a twin-roller (with a diameter of $180 \mathrm{~mm}$ ) apparatus. The deformation strains were simply calculated as $\epsilon=2 \ln \left(t_{0} / t\right) / \sqrt{3}$, where $t_{0}$ and $t$ are initial thickness and final thickness, respectively.

To evaluate overall thermal behaviors associated with grain growth, differential scanning calorimetry (DSC) curves were obtained on a NETZSCH STA449C thermoanalyzer instrument at a heating rate of $20 \mathrm{~K} \cdot \mathrm{min}^{-1}$ and purged by pure Ar with $99.999 \%$ purity at $80 \mathrm{ml} \cdot \mathrm{min}^{-1}$.

Quantitative microstructural characterization of the as-received and deformed samples was investigated by transmission electron microscopy (TEM) and $\mathrm{x}$-ray diffraction (XRD). For the accuracy of the experimental results, special attention was paid to the TEM sample preparation. Samples for TEM observation were prepared by double-jet electropolishing at 20V (DC) using a solution of nitric acid and methanol $(\mathrm{V}: \mathrm{V}=1: 4)$ at $-30^{\circ} \mathrm{C}$. The size distribution and morphology of nanograins were examined on a Zeiss Libra 200FE TEM under an accelerating voltage of $200 \mathrm{kV}$. XRD spectra were obtained on a Rigaku D/MAX 2500PC diffractometer ( $\mathrm{Cu} \mathrm{K} \alpha$ radiation) operating in a step scan mode in the range of $2 \theta=40-100^{\circ}$, using an accelerating voltage of $40 \mathrm{KV}$ and a current of $150 \mathrm{~mA}$. Average grain size and dislocation density were quantitatively determined by x-ray line profile analysis.

\section{Results and discussion}

Figure 2 depicts the DSC curves of the as-received NC Ni and Ni-Fe samples with almost similar grain size distribution. For the NC Ni, two small exothermic peaks at $\sim 109^{\circ} \mathrm{C}$

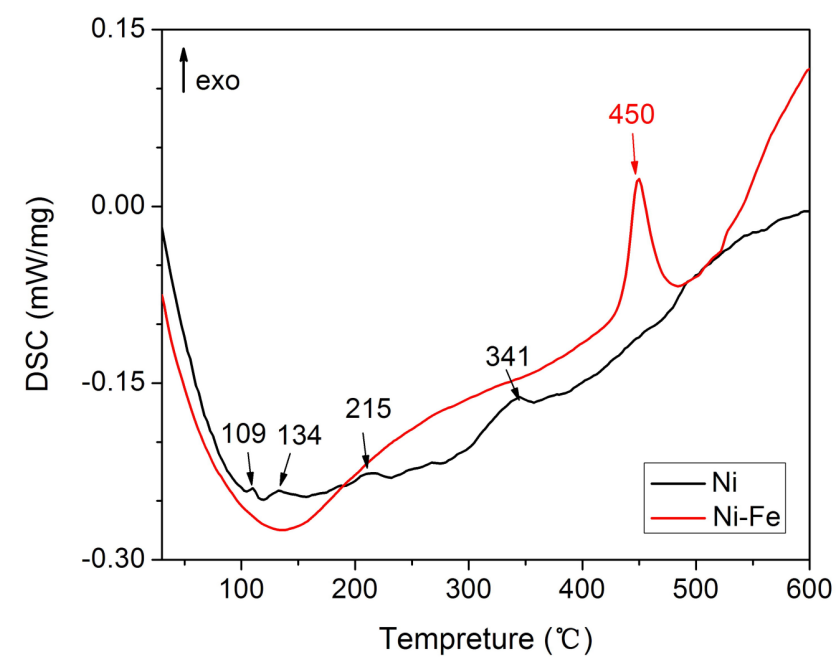

Figure 2: Typical DSC curves of NC Ni and Ni-Fe samples at a heating rate of $20 \mathrm{~K} \cdot \mathrm{min}^{-1}$. 
and $\sim 134^{\circ} \mathrm{C}$ are found below $200^{\circ} \mathrm{C}$, indicating the initiation of grain growth. As the temperature continues to raise, two broad exothermic peak with a peak temperature of $\sim 215^{\circ} \mathrm{C}$ and $\sim 341^{\circ} \mathrm{C}$ are believed to be due to continuous grain growth. In contrast, it can be clearly seen that the DSC of NC Ni-Fe has only one sharp exothermic peak at $\sim 450^{\circ} \mathrm{C}$. The difference in the DSC between NC Ni and NiFe agrees well with the previous reports.

Figure 3 shows the TEM analysis results on the grain size distribution of NC Ni and Ni-Fe samples. Through comparative analysis, it is found that the two as-received samples have nearly the same size distribution and most of grain size does not exceed $30 \mathrm{~nm}$. The average grain size is determined to be $\sim 22 \mathrm{~nm}$. However, after the $\epsilon=0.15$ rolling deformation, there is a discrepancy in the evolution of size distribution. For the deformed NC Ni sample, the average grain size increases slowly to $\sim 29 \mathrm{~nm}$. Analysis of distribution indicates the number of grains with sizes ranging $0-20 \mathrm{~nm}$ decreases obviously, whereas the number of grains with sizes ranging 20-50nm increases correspondingly as compared to undeformed state. For deformed NC
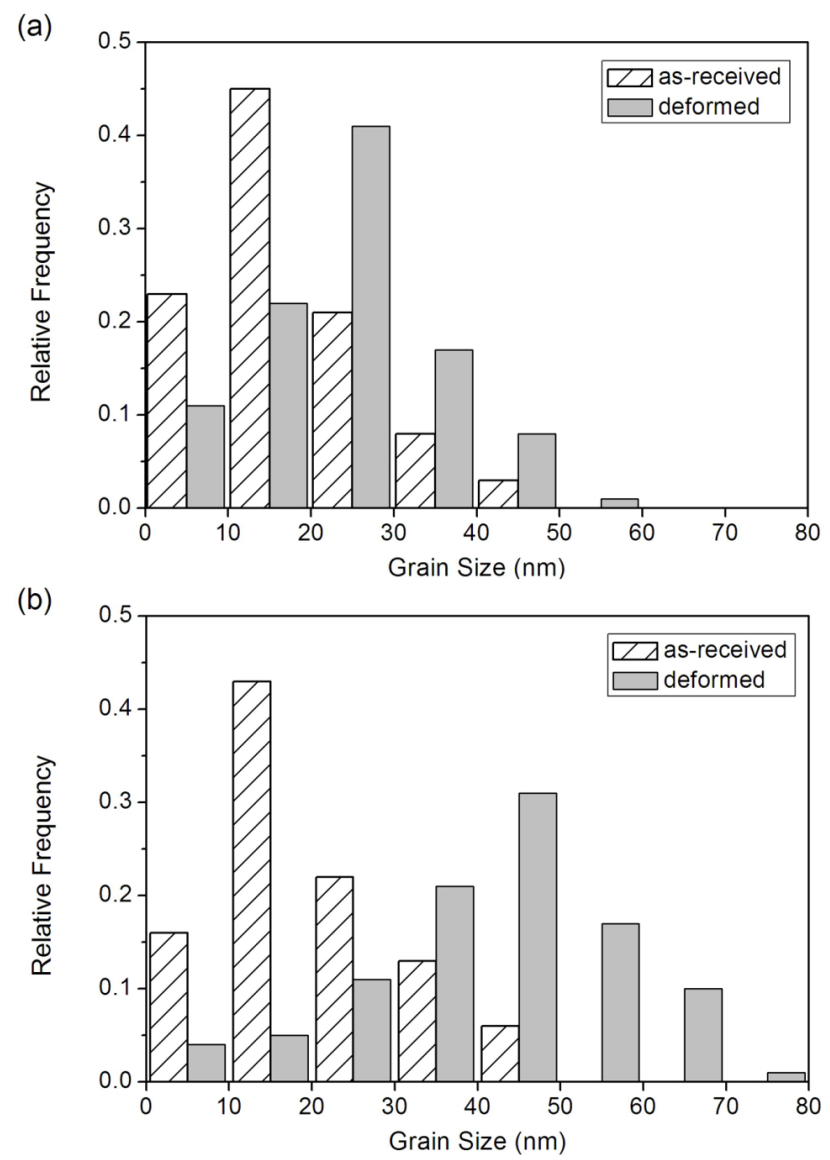

Figure 3: Statistical grain size distributions for the as-received and deformed ( $\epsilon=0.15$ ) samples: (a) NC Ni; (b) NC Ni-Fe alloy.
$\mathrm{Ni}-\mathrm{Fe}$ sample, the average grain size increases rapidly to $\sim 45 \mathrm{~nm}$ and most of grain size was more than $30 \mathrm{~nm}$. In addition, from the value of grain size distribution of deformed samples, it is further noteworthy that the grain growth rate of NC Ni-Fe should be higher than that of NC Ni.

To interpret the observed discrepancy in grain growth rate between NC Ni and Ni-Fe, the XRD results are shown in Figure 4. According to XRD quantitation, the full width at half maximum (FWHM) values measured for (111) and (200) reflection planes of deformed NC Ni and Ni-Fe are markedly reduced. Particularly in NC Ni-Fe sample, the values of FWHM decline even more sharply. Such a decrease in FWHM implies that the growth of nanograins and this is in agreement with the TEM observation. As mentioned previously, grain rotation and orientation could also have affected the nanograin growth behavior. The change of grain orientation caused by rotation is simply evaluated by the $(200) /(111)$ diffraction intensity ratios $\left(I_{200} / I_{111}\right)$. The $I_{200}$ $/ I_{111}$ ratio of as-received NC Ni is 1.26, indicating a significant (200) preferred orientation compared with the data in the JCPDS standard card (PDF\#04-0850). When the sample undergoes deformation, the (200) preferred orientation strengthens and generally remains at a level of 2.20. In the case of NC Ni-Fe, the $I_{200} / I_{111}$ ratio of as-received sample is only 0.58 , which is slightly higher than the standard value. However, with increasing deformation, the $I_{200} /$ $I_{111}$ ratio has shown a strong uptrend and reaches a maximum value of 1.15 at $\epsilon=0.15$. Note that the $I_{200} / I_{111}$ ratio of $\epsilon=0.15$ deformed NC Ni-Fe sample is lower than that of undeformed NC Ni sample.

Microstructural parameters such as grain size and dislocation density are shown in Figure 5. The average grain size of as-received NC samples is determined to be $\sim 20 \pm 2 \mathrm{~nm}$ by XRD, which is consistent with TEM analysis. Grain size evolution depicts an increase of the average grain size during the whole deformation process. Subjected to $\epsilon=0.15$ rolling deformation, the average grain size of NC Ni increases to $\sim 27 \pm 2 \mathrm{~nm}$, whereas the average grain size of NC Ni-Fe increases to $\sim 42 \pm 4 \mathrm{~nm}$. Additionally, the dislocation density of NC Ni-Fe is also significantly higher than that of NC Ni before and after deformation. From a previous analysis of stacking fault energy effect on defect formation, it is energetically favorable for Ni-Fe alloy, which has a relatively low stacking fault energy, successively emitting partial dislocations from grain boundaries [80].

Based on the above data, the discrepancy in grain growth rate between $\mathrm{NC} \mathrm{Ni}$ and $\mathrm{Ni}-\mathrm{Fe}$ could be well explained by stress assisted grain rotation mechanism. Nonetheless, for the same material, deformation strain may have important implications for predicting the devel- 
(a)

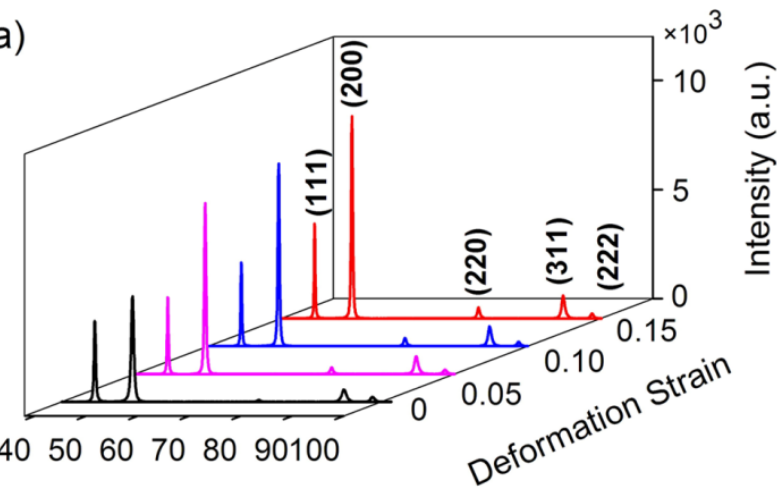

2Theta (degrees)

(c)

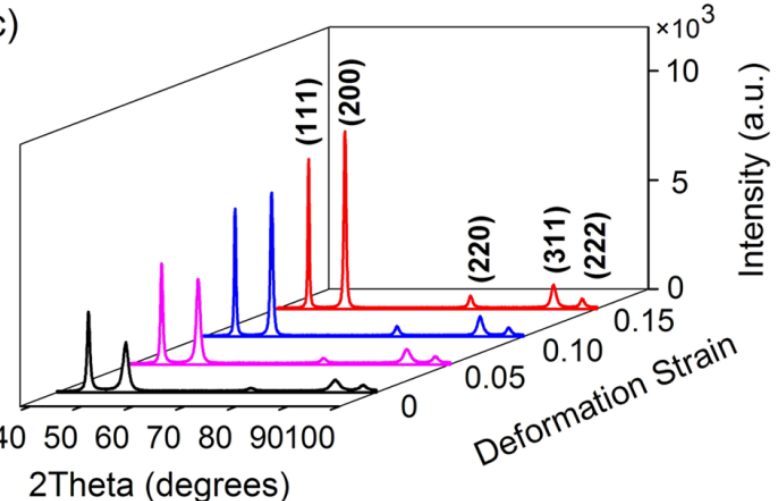

(b)

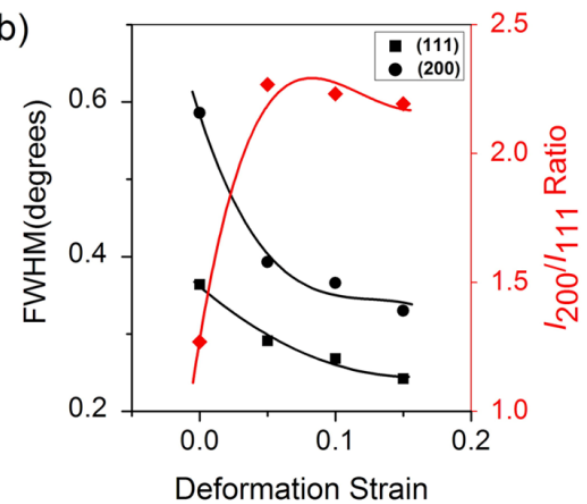

(d)

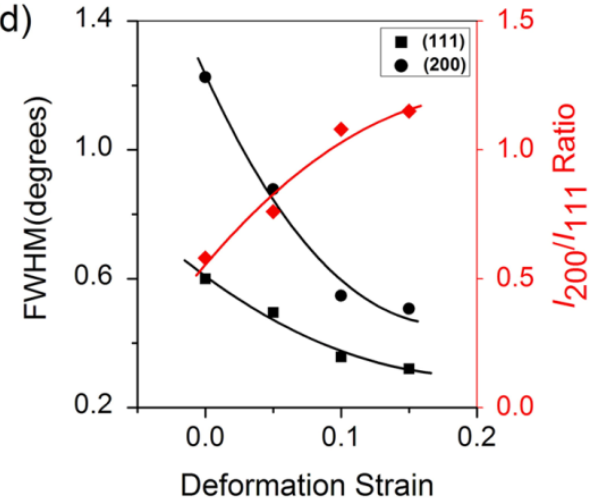

Figure 4: XRD patterns of (a) NC Ni and (c) NC Ni-Fe samples at various deformation stains. The corresponding (200)/(111) diffraction intensity ratio (1200 / I111) and FWHMs of (111) and (200) diffraction planes with increasing strain are shown in (b) NC Ni and (d) NC Ni-Fe, respectively.

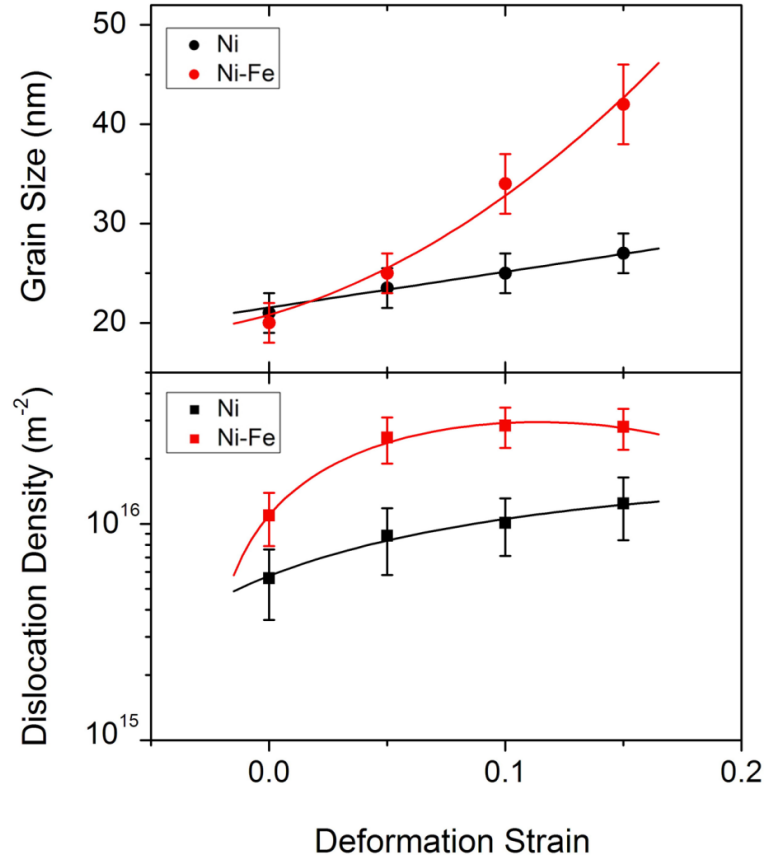

Figure 5: Evolutions of grain size and dislocation density as a function of deformation strain for NC Ni and Ni-Fe samples. opment of grain growth. However, in the case of different materials, deformation strain is no longer to be an important factor to examine the discrepancy in the grain growth behavior. Thereupon the stress required to actually deform the sample should be taken into consideration. According to the results of previous studies, the stress required to continue the rolling deformation process of $\mathrm{NC} \mathrm{Ni}$ and $\mathrm{Ni}-\mathrm{Fe}$ is $\sim 1.4 \mathrm{GPa}$ and $\sim 1.6-1.9 \mathrm{GPa}$, respectively [80]. Under such high stress, solute limited grain boundary mobility will become less of a problem for the NC Ni-Fe sample. Owing to the high stress level, enhanced dislocation motion and pronounced grain rotation, the grain growth rate of $\mathrm{Ni}-\mathrm{Fe}$ alloy would be indeed higher than that of pure Ni.

\section{Conclusion}

In this review, the grain growth behaviors and the underlying mechanisms of bulk electrodeposited nanocrystalline nickel and nickel-iron alloys have been briefly overviewed. The effects of some important factors on grain growth behavior are described. There are two main types 
of grain growth behaviors, namely, thermally-induced grain growth and stress-induced grain growth. During the thermal-induced grain growth process, mechanism of grain boundary migration is well known to play a key role. Under the similar heat treatment conditions, due to grain boundary mobility with solute drag, only very limited grain growth can occur in nanocrystalline nickel-iron alloys, as compared to pure nanocrystalline nickel. Nonetheless, in the case of stress-induced grain growth process, there are a variety of mechanisms that have appeared in samples with various deformation histories. In particular, room temperature rolling deformation has been performed on nanocrystalline nickel and $\mathrm{Ni}-20 \% \mathrm{Fe}$ alloy with nearly the same grain-size distribution and average grain size. After comparing the results, it is found that nanocrystalline nickel is much more prone to rapid grain growth than nanocrystalline Ni-20\%Fe alloy. However, nanocrystalline nickel exhibits slow grain growth during the deformation. Due to the existence of high stress level, enhanced dislocation motion and pronounced grain rotation, the grain growth of nanocrystalline $\mathrm{Ni}-20 \% \mathrm{Fe}$ is more pronounced.

Acknowledgement: This work was supported by the National Natural Science Foundation of China (No.51601026).

\section{References}

[1] N. Wang, Z. Wang, K.T. Aust, and U. Erb, Acta Metall. Mater., 43 (1995) 519-528.

[2] J.L. Mccrea, G. Palumbo, G.D. Hibbard, and U. Erb, Rev. Adv. Mater. Sci., 5 (2003) 252-258.

[3] H. Feng, Q.H. Fang, L.C. Zhang, and Y.W. Liu, Int. J. Plast., 42 (2013) 50-64.

[4] V. Yamakov, D. Wolf, S.R. Phillpot, A.K. Mukherjee, and H. Gleiter, Nature Mater., 3 (2004) 43-47.

[5] G.M. Cheng, W.W. Jian, W.Z. Xu, H. Yuan, P.C. Millett, and Y.T. Zhu, Mater. Res. Lett., 1 (2013) 26-31.

[6] B. Yang, H. Vehoff, and R. Pippan, Mater. Sci. Forum, 633-634 (2010) 85-98.

[7] H. Li, F. Ebrahimi, H. Choo, and P.K. Liaw, J. Mater. Sci., 41 (2006) 7636-7642.

[8] Y.T. Zhu and T.G. Langdon, Mater. Sci. Eng. A, 409 (2005) 234 242.

[9] N.L. Okamoto, D. Kashioka, T. Hirato, and H. Inui, Int. J. Plast., 56 (2014) 173-183.

[10] H. Li, Y. Liang, L. Zhao, J. Hu, S. Han, and J. Lian, J. Alloys Compd., 709 (2017) 566-574.

[11] E.A. Holm and S.M. Foiles, Science, 328 (2010) 1138-1141.

[12] J. Li, J. Wang, and G. Yang, Scripta Mater., 60 (2009) 945-948.

[13] U. Klement, U. Erb, A.M. El-Sherik, and K.T. Aust, Mater. Sci. Eng. A, 203 (1995) 177-186.
[14] N. Wang, Z. Wang, K.T. Aust, and U. Erb, Acta Mater., 45 (1997) 1655-1669.

[15] M. Thuvander, M. Abraham, A. Cerezo, and G.D.W. Smith, Mater. Sci. Technol., 17 (2001) 961-970.

[16] G.D. Hibbard, J.L. Mccrea, G. Palumbo, K.T. Aust, and U. Erb, Scripta Mater., 47 (2002) 83-87.

[17] Y.M. Wang, S. Cheng, Q.M. Wei, E. Ma, T.G. Nieh, and A. Hamza, Scripta Mater., 51 (2004) 1023-1028.

[18] K. Zhang, J.R. Weertman, and J.A. Eastman, Appl. Phys. Lett., 87 (2005) 061921.

[19] F. Ebrahimi and H. Li, Scripta Mater., 55 (2006) 263-266.

[20] M.J.N.V. Prasad, S. Suwas, and A.H. Chokshi, Mater. Sci. Eng. A, 503 (2009) 86-91.

[21] Y.B. Wang, J.C. Ho, Y. Cao, X.Z. Liao, H.Q. Li, Y.H. Zhao, E.J. Lavernia, S.P. Ringer, and Y.T. Zhu, Appl. Phys. Lett., 94 (2009) 091911.

[22] A. Torrents, H. Yang, and F.A. Mohamed, Metall. Mater. Trans. A, 41 (2010) 621-630.

[23] Z.H. Cao, P.Y. Li, L. Wang, Z.H. Jiang, and X.K. Meng, Appl. Phys. A, 109 (2012) 613-619.

[24] Y.D. Zheng, P.Q. Dai, W.C. Xu, and S.R. Hu, Mater. Sci. Technol., 27 (2013) 1793-1797.

[25] J. Kacher, K. Hattar, and I.M. Robertson, Mater. Sci. Eng. A, 675 (2016) 110-119.

[26] A.N. Aleshin, Phys. Sol. St., 58 (2016) 413-420.

[27] M.T. Schmitt, J.E. Hoffmann, and D. Eifler, Phys. Stat. Sol., 210 (2013) 864-869.

[28] H.Q. Li and F. Ebrahimi, Acta Mater., 51 (2003) 3905-3913.

[29] F. Czerwinski, H. Li, M. Megret, J.A. Szpunar, D.G. Clark, and U. Erb, Scripta Mater., 37 (1997) 1967-1972.

[30] A.N. Aleshin, Russ. Metall., 2008 (2008) 286-293.

[31] G. Gottstein, D.A. Molodov, and L.S. Shvindlerman, Interface Sci., 6 (1998) 7-22.

[32] A.R. Kalidindi, T. Chookajorn, and C.A. Schuh, JOM, 67 (2015) 2834-2843

[33] V.Y. Novikov, Mater. Lett., 159 (2015) 510-513.

[34] D.S. Gianola, B.G. Mendis, X.M. Cheng, and K.J. Hemker, Mater. Sci. Eng. A, 483-484 (2008) 637-640.

[35] Y.B. Park, S.H. Hong, C.S. Ha, H.Y. Lee, and T.H. Yim, Mater. Sci. Forum, 408-412 (2002) 931-936.

[36] S. Chakraborty, M. Settem, and S.B. Sant, Mater. Express, 3 (2013) 99-108.

[37] U. Klement and M.D. Silva, J. Alloys Compd., 434-435 (2007) 714-717.

[38] G. Gottstein and F. Schwarzer, Mater. Sci. Forum, 94-96 (1992) 187-208.

[39] N. Ono, K. Kimura, and T. Watanabe, Acta Mater., 47 (1999) 1007 1017.

[40] H.T. Ni, X.Y. Zhang, X. Chen and L. Yu, Mater. Sci. Technol., 28 (2012) 754-759.

[41] S.L. Thomas, A.H. King, and D.J. Srolovitz, Acta Mater., 113 (2016) 301-310.

[42] L. Li, T. Ungár, Y.D. Wang, J.R. Morris, G. Tichy, J. Lendvai, Y.L. Yang, Y. Ren, H. Choo, and P.K. Liaw, Acta Mater., 57 (2009) 4988 5000.

[43] N.P. Gurao and S. Suwas, Philos. Mag., 91 (2011) 798-817.

[44] X.L. Wu, Y.T. Zhu, Y.G. Wei, and Q. Wei, Phys. Rev. Lett., 103 (2009) 205504.

[45] A. Kulovits, S.X. Mao, and J.M.K. Wiezorek,Acta Mater., 56 (2008) 4836-4845. 
[46] L. Li, T. Ungár, L.S. Toth, W. Skrotzki, Y.D. Wang, Y. Ren, H. Choo, Z. Fogarassy, X.T. Zhou, and P.K. Liaw, Metall. Mater. Trans. A, 47 (2016) 6632-6644.

[47] X. Shen and Z. Xu, Mater. Sci. Eng. A, 528 (2011) 7878-7886.

[48] S. Brandstetter, K. Zhang, A. Escuadro, J.R. Weertman, and H.V. Swygenhoven, Scripta Mater., 58 (2008) 61-64.

[49] G.J. Fan, Y.D. Wang, L.F. Fu, H. Choo, P.K. Liaw, Y. Ren, and N.D. Browning, Appl. Phys. Lett., 88 (2006)171914.

[50] G.J. Fan, L.F. Fu, H. Choo, P.K. Liaw, and N.D. Browning, Acta Mater., 54 (2006) 4781-4792.

[51] X. Wu, Y.T. Zhu, M.W. Chen, and E. Ma, Scripta Mater., 54 (2006) 1685-1690.

[52] Y.B. Wang, B.Q. Li, M.L. Sui, and S.X. Mao, Appl. Phys. Lett., 92 (2008) 011903.

[53] G.J. Tucker and S.M. Foiles, Mater. Sci. Eng. A, 571 (2013) 207-214.

[54] Y.B. Wang, J.C. Ho, X.Z. Liao, H.Q. Li, S.P. Ringer, and Y.T. Zhu, Appl. Phys. Lett., 94 (2009) 011908.

[55] X.Z. Liao, A.R. Kilmametov, R.Z. Valiev, H. Gao, X. Li, A.K. Mukherjee, J.F. Blingert, and Y.T. Zhu, Appl. Phys. Lett., 88 (2006) 021909.

[56] B.L. Boyce and H.A. Padilla, Metall. Mater. Trans. A, 42 (2011) 1793-1804.

[57] T.A. Furnish, B.L. Boyce, J.A. Sharon, C.J. O’Brien, B.G. Clark, C.J. Arrington, and J.R. Pillars, J. Mater. Res., 31 (2016) 740-752.

[58] T.A. Furnish, A. Mehta, D.V. Campen, D.C. Bufford, K. Hattar, and B.L. Boyce, J. Mater. Sci., 52 (2017) 46-59.

[59] K.S. Kumar, S. Suresh, M.F. Chisholm, J.A. Horton, and P. Wang, Acta Mater., 51 (2003) 387-405.

[60] S. Cheng, Y. Zhao, Y. Guo, Y. Li, Q. Wei, X.L. Wang, Y. Ren, P.K. Liaw, H. Choo, and E.J. Lavernia, Adv. Mater., 21 (2009) 5001-5004.

[61] S. Ni, G. Sha, Y.B. Wang, X.Z. Liao, S.N. Alhajeri, H.Q. Li, Y.T. Zhu, T.G. Langdon, and S.P. Ringer, Mater. Sci. Eng. A, 528 (2011) 7500 7505.

[62] H.T. Ni, X.Y. Zhang, and P.Y. Li, Mater. Sci. Eng. A, 538 (2012) 302-305.

[63] T. Chan, Y. Zhou, I. Brooks, G. Palumbo, and U. Erb, J. Mater. Sci., 49 (2014) 3847-3859.
[64] Y. Zhang, G.J. Tucker, and J.R. Trelewicz, Acta Mater., 131 (2017) 39-47.

[65] G. Sharma, J. Varshney, A.C. Bidaye, and J.K. Chakravartty, Mater. Sci. Eng. A, 539 (2012) 324-329.

[66] J. Li, A.K. Soh, and X. Wu, Scripta Mater., 78-79 (2014) 5-8.

[67] Z.Y. Zhang, Mod. Phys. Lett. B, 31 (2017) 1750237.

[68] F. Wang, J. Zhao, P. Huang, A.S. Schneider, T.J. Lu, and K.W. Xu, J. Nanomater., 2013 (2013) 934986.

[69] B. Wang, M.T. Alam, and M.A. Haque, Scripta Mater., 71 (2014) 1-4.

[70] I.A. Ovid'ko and A.G. Sheinerman, J. Mater. Sci., 51 (2016) 64446451.

[71] D. Farkas, S. Mohanty, and J. Monk, Mater. Sci. Eng. A, 493 (2008) 33-40.

[72] D. Farkas, A. Frøseth, and H.V. Swygenhoven, Scripta Mater., 55 (2006) 695-698

[73] T.J. Rupert, D.S. Gianola, Y. Gan, and K.J. Hemker, Science, 326 (2009) 1686-1690.

[74] A.J. Haslam, S.R. Phillpot, D. Wolf, D. Moldovan, and H. Gleiter, Mater. Sci. Eng. A, 318 (2001) 293-312.

[75] S.V. Bobylev and I.A. Ovid'Ko, Rev. Adv. Mater. Sci., 41 (2015) 20-34.

[76] H.T. Ni and X.Y. Zhang, Philos. Mag. Lett., 92 (2012) 202-210.

[77] D.S. Gianola, S. Van Petegem, M. Legros, S. Brandstetter, H. Van Swygenhoven, and K.J. Hemker, Acta Mater., 54 (2006) 2253. 2263.

[78] D.L. Olmsted, E.A. Holm, and S.M. Foiles, Acta Mater., 57 (2009) 3704-3713.

[79] M.J.N.V. Prasad and A.H. Chokshi, Scripta Mater., 67 (2012) 133 136.

[80] H.T. Ni and X.Y. Zhang, Mater. Sci. Eng. A, 541 (2012) 216-221.

[81] H. Ni, J. Zhu, Z. Wang, and H. Lv, Rev. Adv. Mater. Sci., 52 (2017) 49-53.

[82] H. Li and F. Ebrahimi, Mater. Sci. Eng. A, 347 (2003) 93-101. 